\title{
Chlamydomonas mutant hpm91 lacking PGR5 is a scalable and valuable strain for algal hydrogen $\left(\mathrm{H}_{2}\right)$ production
}

Peng Liu ${ }^{\mathrm{a}, \mathrm{e}, 1}$, De-Min Ye $\mathrm{e}^{\mathrm{a}, \mathrm{e}, 1}$, Mei Chen ${ }^{\mathrm{a}, 1}$, Jin Zhang ${ }^{\mathrm{a}, \mathrm{e}, 1}$, Xia-He Huang ${ }^{\mathrm{b}}$, Li-Li Shen ${ }^{\mathrm{a}, \mathrm{e}}, \mathrm{Ke}-\mathrm{Ke} \mathrm{Xia}^{\mathrm{c}}$, Xiao-Jing $\mathrm{Xu}^{\mathrm{c}, \mathrm{e}}$, Yong-Chao $\mathrm{Xu}^{\mathrm{d}, \mathrm{e}}$, Ya-Long Guo $^{\mathrm{d}}$, Ying-Chun Wang ${ }^{\mathrm{b}, *}$, and Fang Huang ${ }^{\mathrm{a}, *, 2}$

${ }^{a}$ Photosynthesis Research Center, Key Laboratory of Photobiology, Institute of Botany, Chinese Academy of Sciences, Beijing 100093, China; ${ }^{b}$ State Key Laboratory of Molecular Developmental Biology, Institute of Genetics and Developmental Biology, Chinese Academy of Sciences, Beijing 100101, China; ${ }^{c} B G I-S h e n z h e n$, Shenzhen 518083, China; 'State Key Laboratory of Systematic and Evolutionary Botany, Institute of Botany, Chinese Academy of Sciences, Beijing 100093, China; ${ }^{e}$ University of Chinese Academy of Sciences, Beijing 100049, China

${ }^{1}$ These authors contributed equally to this work

${ }^{2}$ Lead contact

*Corresponding authors: F. H.: e-mail, fhuang@ibcas.ac.cn; phone, +86-10-

62836692; fax, +86-10-62594363. Y.-C. W.: e-mail, ycwang@genetics.ac.cn; phone, +86-10-64806149. 


\section{Summary}

Clean and sustainable $\mathrm{H}_{2}$ production is essential toward a carbon-neutral world. $\mathrm{H}_{2}$ generation by Chlamydomonas reinhardtii is an attractive approach for solar- $\mathrm{H}_{2}$ from $\mathrm{H}_{2} \mathrm{O}$. However, it is currently not scalable because of lacking ideal strains. Here, we explore hpm91, a previously reported PGR5-deletion mutant with remarkable $\mathrm{H}_{2}$ production, that possesses numerous valuable attributes towards large-scale application and in-depth study issues. We show that hpm91 is at least 100-fold scalable (upto 10 liter) with $\mathrm{H}_{2}$ collection sustained for averagely 26 days and $7287 \mathrm{ml}$ $\mathrm{H}_{2} / 10 \mathrm{~L}-\mathrm{HPBR}$. Also, hpm91 is robust and active over the period of sulfur-deprived $\mathrm{H}_{2}$ production, most likely due to decreased intracellular ROS relative to wild type. Moreover, quantitative proteomic analysis revealed its features in photosynthetic antenna, primary metabolic pathways and anti-ROS responses. Together with success of new high- $\mathrm{H}_{2}$-production strains derived from $h p m 91$, we highlight that $h p m 91$ is a potent strain toward basic and applied research of algal- $\mathrm{H}_{2}$ photoproduction.

\section{Keywords:}

C. reinhardtii, hpm91 mutant, scale-up $\mathrm{H}_{2}$ production, $\mathrm{ROS}$, quantitative proteomics, hpm91-derived mutant

\section{Introduction}

Hydrogen $\left(\mathrm{H}_{2}\right)$ derived from $\mathrm{H}_{2} \mathrm{O}$ is a clean and versatile energy carrier that could be obtained sustainably through sunlight-driven chemical and biological means such as photocatalysis and algal photoproduction (Bayro-Kaiser and Nelson, 2017; Nishiyama et al., 2021). Under anaerobic condition, $\mathrm{H}_{2}$ photoproduction occurs in microalgae such as Chlamydomonas reinhardtii (henceforth referred to as Chlamydomonas) virtually via water-oxidation in visible light (Gfeller and Gibbs, 1984; Greenbaum, 1988). $\mathrm{H}_{2}$ formation is through the catalytic activity of (Fe-Fe) hydrogenases (Forestier et al., 2003) induced under anoxia, using mainly photosynthetic electrons on the acceptor side of photosystem I (PSI) in reduction of 
protons into $\mathrm{H}_{2}$ (Forestier et al., 2003; Ghirardi, 2015). As a result, renewable $\mathrm{H}_{2}$ production is achieved in the organisms using energy input from solar irradiation and electrons derived from photosynthetic water-splitting reaction. In wild-type Chlamydomonas strains, however, $\mathrm{H}_{2}$ photoproduction is only transient in anoxia or sustains for several days under sulfur-deprived anaerobic condition (Ghirardi, 2015; Kruse et al., 2005; Melis et al., 2000). This is a major obstacle to make this biosystem economically viable for solar- $\mathrm{H}_{2}$ production.

Using various genetic strategies, dozens of Chlamydomonas mutants with increased $\mathrm{H}_{2}$ production have been isolated over the last decades. Several of them are reasonably well documented such as the state transition mutant (stm6), truncated light-harvesting antenna mutant (tlal), D1 mutant (Kosourov et al., 2011; Kruse et al., 2005; Scoma et al., 2012; Volgusheva et al., 2013), and the pgr mutants named as pgrll (proton gradient regulation like 1), pgr5 (proton gradient regulation 5) and hpm91 (Chen et al., 2016; 2019; Steinbeck et al., 2015; Tolleter et al., 2011). Of those, the $p g r$ mutants are of considerable interest because their target gene products are intimately involved in the PGR5-dependent branch of photosynthetic cyclic electron flow (CEF), which is the major route of CEF (Chen et al., 2016;

Schwenkert et al., 2022; Steinbeck et al., 2015; Takahashi et al., 2013; Tolleter et al., 2011). While a negative correlation between the $\mathrm{CEF}$ and $\mathrm{H}_{2}$ photoproduction was initially indicated in the stm6 mutant deficient in $M O C 1$ gene which encodes an assembly factor of the mitochondrial respiratory chain (Schonfeld et al., 2004), more direct experimental evidence was obtained via analysis of pgr (pgrl1, pgr5, hpm91) as well as $f n r$ (ferredoxin-NADPH reductase) mutants (Sun et al., 2013; Yacoby et al., 2011). PGRL1 and FNR have been identified in the CEF supercomlex (Iwai et al., 2010) and PGR5 are known being a regulatory protein involved in the CEF branch (Munekage et al., 2002; Suorsa et al., 2012), for which the mechanism of action is currently not yet clear (Schwenkert et al., 2022).

Most remarkably, the hpm91 mutant sustains $\mathrm{H}_{2}$ photoproduction for 25 days (Chen et al., 2016). Although an inverse relationship was revealed between PGR5 levels and $\mathrm{H}_{2}$ production, and the prolonged $\mathrm{H}_{2}$ evolution was largely attributed to the 
enhanced anti-ROS capability protecting the photosynthetic electron transport chain from photooxidative damage (Chen et al., 2016), questions arise as i) whether the phenotype of hpm91 is stable in large scale setting-ups? ii) how intracellular ROS content of hpm91 is altered during sulfur-deprived $\mathrm{H}_{2}$ photoproduction? iii) what are the proteomic characteristics of hpm91 under such conditions. We report here the performance of hpm91 in a large scale (upto 10 liter) $\mathrm{H}_{2}$-photobioreactor (HPBR) systems. We also describe new findings of hpm91 at the level of systems biology associated with the intial analytical scale HPBR $(100 \mathrm{ml})$. We highlight the hpm 91 as a valuble algal strain not only for basic research of understanding the molecular mechanisms of $\mathrm{H}_{2}$ photoproduction but also for development of economically viable solar-powered $\mathrm{H}_{2}$ production systems.

\section{Results and Discussion}

\section{$\mathrm{H}_{2}$ production of $h p m 91$ was large-scalable}

Previous experimental results and literature survey revealed top ranking of $h p m 91$ among Chlamydomonas mutants with enhanced $\mathrm{H}_{2}$ photoproduction under sulfurdeprived condition (Chen et al., 2016; 2019). To determine its potential towards application, we carried out scaling-up and gas-handling experiments in the laboratory using hpm91 (Fig. 1; Movie S1). Initially, the experiments were performed with $\mathrm{H}_{2}$-photobioreactors (HPBR) of scaling-up 10-, 20-, and 30-times (from $100 \mathrm{ml}$ ) using chlorophyll concentration of $25 \mu \mathrm{g} / \mathrm{ml}$ as previously (Chen et al., 2016; 2019). We found the highest yield of $\mathrm{H}_{2}$ from the $3 \mathrm{~L}-\mathrm{HPBR}$ as well as a positive correlation between the yield and size of HPBR (Fig. 1A, B). These results encouraged us to extend the scaling-up directly to 10L-HPBR (headspace $1700 \mathrm{ml}$, light path $22 \mathrm{~cm}$, illuminated on 3 sides) and to investigate its $\mathrm{H}_{2}$ production profiles. To reduce potential shading effects (Hemschemeier et al., 2009; Kosourov et al., 2002) and low-light stress on algal cells, we reasonably reduced initial chlorophyll concentration (ICC) to $20 \mu \mathrm{g} / \mathrm{ml}$ of cell suspension and cultured under increased light irradiance $\left(130 \mu \mathrm{E} \mathrm{m}^{-2} \mathrm{~s}^{-1}\right)$ for $\mathrm{H}_{2}$ production. 
Fig. 1C compares $\mathrm{H}_{2}$ photoproduction of hpm91 and wild type in 10L-HPBR under identical cultural condition. In contrast to wild type, which generated few gas bubbles with collectable $\mathrm{H}_{2}$ quantity negligible, we observed a bulk of $\mathrm{H}_{2}$ bubbles in hpm91 after 3-4 days of sulfur deprivation with the gas collectable for up to 33 days (Fig. 1C). To confirm these results, experiments were repeated twice using different batch of algal cells. The data shows that continuous $\mathrm{H}_{2}$ collection from $\mathrm{hpm} 91$ could be achieved at an average of 28 days (SI Appendix, Table S1), which was the longest duration of $\mathrm{H}_{2}$ production under sulfur deprivation reported thus far for Chlamydomonas. These results promoted us to explore more possibilities to enhance $\mathrm{H}_{2}$ production of hpm91 in 10L-HPBR.

Indeed, further increase of light intensity to $230 \mu \mathrm{E} \mathrm{m}^{-2} \mathrm{~s}^{-1}$ apparently enhanced $\mathrm{H}_{2}$-producing capability of $h p m 91$. Compared to that under lower light $\left(130 \mu \mathrm{E} \mathrm{m}^{-2} \mathrm{~s}^{-}\right.$ ${ }^{1}$ ), output of $\mathrm{H}_{2}$ increased up to $57.9 \%$ (SI Appendix, Table S1). Because $\mathrm{H}_{2}$ output stopped in most cases around 25 day of sulfur deprivation, we then compared its $\mathrm{H}_{2}$ evolution profiles within the period. As shown in Fig. 1D, the gereral kinetic pattern was largely similar but higher rate and extended linear increasing period ( $480 \mathrm{~h} v s 420$ h) of $\mathrm{H}_{2}$ production was observed for those cultured under increased light. An average $\mathrm{H}_{2}$ output reached to $7287 \mathrm{ml} / 10 \mathrm{~L}-\mathrm{HPBR}$, which was $50.7 \%$ higher than that under lower light (SI Appendix, Table S1). Further experiments verified its essentially pure $\mathrm{H}_{2}$ output which enabled us to make a $\mathrm{H}_{2}$ fuel cell-powered toycar drive using ambient air directly (Movie S1). These results allowed us to address the value of hpm91 in not only basic research but also in advancing bio- $\mathrm{H}_{2}$ photoproduction technology.

\section{Decreased intracellular ROS in hpm91}

Based on visual comparison of cell suspension, cell growth of hpm91 was always better than wild type in both small $(100 \mathrm{ml})$ and large HPBR (1 to $10 \mathrm{~L})$ especially during prolonged period of $\mathrm{H}_{2}$ production. To understand the basis of cell biology, we investigated changes of cell morphology and viability in hpm91 committed to $\mathrm{H}_{2}$ production. Because the small HPBR system was experimentally more efficient, the 
system was of choice for comparative studies between wild type and hpm 91 during $120 \mathrm{~h}$ of $\mathrm{H}_{2}$ production (Fig. 2).

Fig. 2A shows that cells of wild type became largely translucent whereas no such changes were observed in hpm91. This remarkable morphological alteration of wildtype cells was highly similar to earlier observations which was mainly attributed to the substantial loss of endogenous starch and a declined cell viability under such condition (Zhang et al., 2002). Also, culture density of hpm91 was more stable after $24 \mathrm{~h}$ and remained significantly higher than wild type at the end of the measurements (120 h) (Fig. 2B). Moreover, we found decreased portion of dead cells in the culture of hpm91 relative to wild type (SI Appendix, Fig. S1). These results are clear indications of robustness of hpm91 cells towards sulfur-deprived $\mathrm{H}_{2}$ production.

To further elucidate this, we measured intracellular ROS contents of hpm91 and wild type under such conditions (Fig. 2C, D). ROS levels were determined using a MoFlo XDP high-speed flow cytometer (Beckman-Coulter, Inc. USA) by following the manufacturer's instructions. Sample preparation was performed under anoxia with addition of glucose oxidase, catalase and glucose just before flow cytometric measurements (Chen et al., 2019). Average fluorescence intensity of DCF from $3 \times 10^{5}$ cells was recorded and data acquisition and analysis were carried out using Summit 5.2 software (Beckman-Coulter, Inc. USA) (Fig. 2C). Our data shows that intracellular level of ROS in hpm91 remained significantly lower than wild type during $\mathrm{H}_{2}$ prodution. At $120 \mathrm{~h}$, the amount of ROS in hpm91 was only $1 / 3$ of that in wild type (Fig. 2D). These in vivo experimental data are in line with our previous results, showing increased activity of ROS-scvenging enzymes in $h p m 91$ relative to wild type (Chen et al., 2016). Thus, the better cell viability of hpm91 could be largely attributed to its decreased level of ROS. A question raises how this is elicited in the organism under such conditions.

\section{Overview of proteome changes in wild type and hpm91 under sulfur deprivation}

Earlier work revealed preliminary metabolic interplay in wild type and pgr mutants of Chlamydomonas during sulfur-deprived $\mathrm{H}_{2}$ photoproduction (Chen et al., 2010; Melis 
et al., 2000; Steinbeck et al., 2015; Tolleter et al., 2011; Zhang et al., 2002). To understand molecular mechanism of $\mathrm{H}_{2}$ metabolism regulated by PGR5, we then carried out iTRAQ quantitative proteomics of hpm91 and wild-type cells during $120 \mathrm{~h}$ of $\mathrm{H}_{2}$ production. As presented in Fig. 3A, samples were taken at four different time points $(0,24,72$ and $120 \mathrm{~h})$ and total proteins were extracted for protein identification and quantification. A total of 3798 proteins with quantitative data were confidently identified $(\mathrm{FDR}<1 \%)$ as listed in (Dataset S1). Identification was mostly based on minimum of two peptide-hits per protein but considering several proteins such as iron hydrogenase $\mathrm{Hyd} 3$ were probably involved $\mathrm{H}_{2}$ metabolism and numerous functionally important small-sized and/or membrane proteins may possess only one identifiable tryptic peptide in MS analysis, those identified with one-peptide hit were also reasonably included (Dataset $\mathrm{S} 1$ ).

Reproducibility of protein quantitation was verified by hierarchical clustering analysis (Perseus _1.6.0.7) of these proteins obtained with three biological replicates (Fig. 3B). To confirm functional impairment of hpm91 in cyclic electron transfer (CEF), we compared the CEF rates in both strains. The data showed that CEF of hpm91 was significantly decreased relative to wild type (SI Appendix, Fig. S2A). To be more certain with the genetic background of the strains, we performed highthroughput genomic sequencing for wild type $(\mathrm{CC} 400,137 \mathrm{c})$ and the $\operatorname{pgr} 5$ mutants (hpm91, pgr5). The data was deposited at the CNGBdb database (Chen et al., 2020; Guo et al., 2020) (https://db.cngb.org/search; accession No. CNP0002674). Further analysis of reads coverage validates previous mutation mapping (Chen et al., 2016; Johnson et al., 2014) and showed large deletions in PGR5-containing region of hpm91 and pgr5 mutants (SI Appendix, Fig. S2B). Together with the immuno-blot results showing no detectable PGR5 but presence of PGRL1 and FNR in hpm91 (Chen et al., 2016), we clarify that the impaired CEF of hpm91 is arributed to loss of PGR5.

Differentially expressed proteins were determined using a cutoff of 1.2-fold change with significance $(\mathrm{p}<0.05)$, leading to three groups consisting of 529 (group I), 2229 (group II) and 1350 (group III) proteins (Fig. 3C) listed in (Datasets S2-S4). These correspond to three comparisons, i.e. hpm91 at $0 \mathrm{~h} v s$ wild-type at $0 \mathrm{~h}$, any time of- 
wild type $v s$ wild-type at $0 \mathrm{~h}$, and any time of-hpm 91 vs hpm91 at $0 \mathrm{~h}$, representing differentially expressed proteins caused by deletion of PGR5 and by sulfur-deprived anoxia in wild type and hpm91, respectively.

To understand functional significance of the differentially expressed proteins in each group, KEGG and gene ontology (GO) analysis was performed using DAVID Bioinformatic Resources 6.8 (https://david.ncifcrf.gov/summary.jsp), yielding 4 enriched KEGG pathways for group I (Fig. 3D), 30 and 29 enriched biological process (GOPB) for the later two groups, respectively (Fig. 4A, Datasets S5 and S6). Because numerous proteins in the latter two enrichments were multiply or/and with error assignments, we reasonably delineated them into 8 and 9 major groups as (Wang et al., 2012) and shown in (SI Appendix, Table S2 and S3), respectively.

It can be seen in Table 1, deletion of PGR5 caused significant changes in four pathways in Chlamydomonas. Compared to wild type, all the ribosomal proteins and most of those related to nitrogen metablism were higher-expressed in $h p m 91$. The latter may implicate enhanced nitrogen metabolism in hpm91. To test this possibility, we compared phenotype of the two strains under $\mathrm{N}$-starved stress condition. The experimental data showed that both cell growth and photosynthetic capability of hpm91 was indeed better than wild type (SI Appendix, Fig. S2C), revealing another impact of PGR5 on chloroplast biology. More interestingly, we found all the photosynthetic antenna proteins except for LHCA3 was lower-expressed in hpm 91 . Because those account for more than $50 \%$ of LHCI and LHCII proteins in Chlamydomonas (Shen et al., 2019; Su et al., 2019; Suga et al., 2019), our finding of their reduced levels could be an indication of a smaller photosynthetic antenna in hpm91 than wild type. Notably, among the proteins involved in sulfur metabolism only APS reductase APR1 encoded by APR1/MET16 (GutierrezMarcos et al., 1996; Setya et al., 1996), known to be involved in sulfur-starvation response (Ravina et al., 2002; Zhang et al., 2004) was higher-expressed in hpm91 (Table 1).

Comparison of the results in Table S2 and S3 revealed similarities in 5 functional groups, i.e. translation, protein folding, intracelluar protein trafficking, response to cytokinin, and ATP hydrolysis/production, reflected by similar change patterns of 
numerous overlapping proteins in the two strains. Differences were also revealed in 4 of those corresponding to carbon metabolism, photosynthetic antenna, cell redox homeostasis/anti-oxidative systems, as well as nitrogen- and sulfur metabolisms. These are the major proteomic characteristics of $h p m 91$ towards sustained $\mathrm{H}_{2}$ production as described/discussed below.

\section{Proteomic characteristics of $\mathbf{h p m} 91$ during sustained $\mathrm{H}_{2}$ production}

Apparently, loss of PGR5 in hpm91 causes compromised primary carbon metabolism during sustained $\mathrm{H}_{2}$ production. As can be seen in Fig. 4A, 6 biological processes were only enriched in hpm91 during $\mathrm{H}_{2}$ production. These were 'carbohydrate metabolism', 'gluconeogenesis', 'fructose 6-phosphate metabolic process', 'glyoxylate cycle', 'cellular amino acid metabolic process' and 'terpenoid biosynthetic process' with the first one appeared within top-10 rankings, implicating that loss of PGR5 caused more profound alterations of primary carbon metabolism in hpm91 than wild type during sulfur-deprived $\mathrm{H}_{2}$ production. Considering metabolic relevance in Chlamydomonas under anoxia (Yang et al., 2015), the group 'tricarboxylic acid cycle' was thus combined with the first 4 of them (SI Appendix, Table S3). While many of them overlapped with wild type, 16 proteins were exclusively revealed in hpm91 during sustained $\mathrm{H}_{2}$ production. These include the key proteins in the regeneration pathway of Calvin-Benson-Bassham (CBB) cycle (SEBP1), glyoxylate cycle (ICL1), gluconeogenesis (PCK1b |PCK1a), oxidative PPP pathway (oPPP) (TAL1, TAL2), fermentative pathways (PFK1, PFK2, PGI1, PFL1), starch metabolism (AMYA2, AMY-like protein, GHL1, ATF1, PHOB, GPM2), and tricarboxylic acid cycle (IDH1), showing increased trends for the most proteins in the first three and decreased trends in the latter four pathways, respectively (Fig. 4B, upleft pannel). It has been earlier reported by Philipps et al. (Philipps et al., 2011) that loss of PFL1 decreased $\mathrm{H}_{2}$ photoproduction. Our finding of increased amount of PFL1 in hpm91 was in line with this and may suggest a partial contribution of PFL1 to its enhanced $\mathrm{H}_{2}$ production. Also, we found alpha-amylases (encoded by AMYA2, CHLREDRAFT_173725) and glucosamine-fructose-6-phosphate aminotransferase 
(ATF1) as well as phosphorylase PHOB increased at an average of 1.86 to 5.02-fold in hpm91 during $\mathrm{H}_{2}$ production (SI Appendix, Table S3). These enzymes are known to be essential for starch metabolism (Weigelt et al., 2009). While accumulation of PHOB could be correlated to the marked increase of starch contents in hpm91 (Chen et al., 2016), elevated level of the amylases was somehow intriguing because starch breakdown in hpm91 was significantly less than wild type (SI Appendix, Table S3; Chen et al., 2016), excluding the major contribution of ' indirect pathway' on the prolonged $\mathrm{H}_{2}$ production phenotype of $h p m 91$. Moreover, our data revealed downregulated key enzymes (PRK1, FBP1, SEBP1) in or related to CBB cycle in hpm91, suggesting that the main route of carbon fixation was largely repressed towards $\mathrm{H}_{2}$ production. It is possible that the increased levels of amylases as well as GHL1 and ATF1 in hpm91 is to yield various intermediates satisfying increased carbon demand under anoxic conditions (Weigelt et al., 2009). Interestingly, we observed a large variation of the key enzymes in TCA cycle of hpm91, such as malate dehydrogenase MDH4 and subunits of succinate dehydrogenase (SDH1, SDH2, SDH4) (SI Appendix, Table S3). Because rate of TCA flux is in general set by concentrations of substrates and intermediates that provide optimal levels of ATP and NADH rather than only by the abundance of the enzymes, the observed variations could be an indication of dynamic energetic status in hpm91 during sulfur-deprived $\mathrm{H}_{2}$ production.

Also, hpm 91 is characteristic of more pronounced accumulation of photosynthetic core proteins with more reduced PSI antenna during sulfur-deprived $\mathrm{H}_{2}$ production. As shown in Table S3, nearly 50\% of the PSII and PSI proteins were accumulated in hpm91 under sulfur deprivation. These include PsbH, PsbP, PsbQ, PsaA, PsaB, PsaD and PsaF with average values of fold-increase within 3.1 to 25.2. Because $\mathrm{H}_{2}$ evolution profile of wild type and hpm91 was mostly distinct at $120 \mathrm{~h}$ of sulfur deprivation (Chen et al., 2019), the change-fold of this time point was compared between the two strains (Fig. 4B, upright pannel). Compared to wild type, foldincrease values of the three PSII proteins was about 2-times larger in hpm91. Considering that PsbP and PsbQ are essential to the maintenance of water-splitting reaction (Shen, 2015) and PsbH is crucial for stable assembly and optimal function of 
PSII (Trosch et al., 2018; Umena et al., 2011), their greater increase in hpm91 may partially explain its significantly higher residual PSII activity during prolonged $\mathrm{H}_{2}$ production (Chen et al., 2019). Regarding to LHCII proteins, we noted that decrease of LHCBM3, LHCBM6, LHCBM8 were more pronounced in hpm91 under such conditions (Fig. 4B, upright panel).

In PSI, we found that while the fold-increase values of PSI core subunits of hpm91 were either higher (PsaB and PsaF) or comparable (PsaA, PsaD) to wild type, all the LHCA proteins displayed declined trends with greater values of decrease-fold in hpm91 than wild type during $\mathrm{H}_{2}$ production process (Fig. 4B, upright panel). The results strongly suggest that $P G R 5$-deficient $h p m 91$ mutant is an algal strain characteristic of small-sized PSI antenna under not only normal condition (Table 1) but also during sustained sulfur-deprived $\mathrm{H}_{2}$ production. It is generally known that, in wild type, transcriptional regulation of LHC genes plays a central role in antanna size adjustment. To test if this is true for hpm91 mutant, we then carried out qRT-PCR analysis of the genes encoding the LHCA proteins. Our data showed that their mRNA levels were indeed down-regulated during $\mathrm{H}_{2}$ production (SI Appendix, Fig. S3). Taken together, we suggest that mutation of PGR5 caused not only the impaired CEF (SI Appendix, Fig. S2A) and higher residual photosynthetic activity (Chen et al., 2016; 2019) but also significantly reduced PSI antenna (Fig. 4B), leading to its higher enficiency of light utilization than wild type towards $\mathrm{H}_{2}$ photoproduction (Kosourov et al., 2011).

Yet, deletion of PGR5 reinforced cell redox homeostasis and anti-oxidative systems in hpm91 under sulfur deprivation. Based on comparison of Table S2 and S3, higher percentage of up-regulated proteins involved in cell redox homeostasis and/or antioxidative stress responses were found in hpm91 than wild type during $\mathrm{H}_{2}$ production process. Although most of them overlapped with wild type, accumulation of several proteins in TRX superfamily, mitochondrial proteins SCO1 and cytochrome c peroxidase CCPR1 as well as those related to cellular response to oxidative stress was more pronounced in hpm91 than wild type. Strikingly, the amount of TRXh, PDI2, APX1 and CCPR1 increased at least 10-fold in hpm91 during prolonged $\mathrm{H}_{2}$ 
production (Fig. 4B, downleft panel). Together with the previous finding of higher activity of ROS-scavenging enzymes in hpm91 (Chen et al., 2016), we conclude that the lower amount of ROS observed in hpm91 (Fig. 2C and D) could be attributed to the marked increase of both protein abundance of those and activity of the ROSscavenging enzymes as well as putatively reduced PSI antenna mentioned above (Lu et al., 2021). A question rises how this is elicited in the PGR5-lacking mutants. We have found earlier that ROS tolerance was increased in PGR5-deficient mutants (hpm91 and pgr5) and proposed a putative link between PGR5 and ROS metabolism in Chlamydomonas (Chen et al., 2016). In line with this, recent studies in Arabidopsis indicate that PGR5 was involved in shaping ROS metabolism during changing in light conditions (Haber et al., 2021). Thus, these experiments suggested, apart from the role of PGR5 as a core modulator of CEF (Schwenkert et al., 2022), an additional role of PGR5 in regulating ROS metabolism. In the present investigation, we also found a unique protein in hpm91, i.e. the EF-hand domain-containing thioredoxin, with an average fold-increase value of 6.13 during sustained $\mathrm{H}_{2}$ photoproduction (SI Appendix, Table S3). Because EF-hand-containing proteins are suggested to be the key transducers mediating calcium $\left(\mathrm{Ca}^{2+}\right)$ signal transduction as a secondary messenger (Day et al., 2002; Kawasaki and Kretsinger, 2017), the remarkable accumulation of the EF-hand domain-containing thioredoxin (encoded by CHLREDRAFT_205510) observed in hpm91 may allow us to propose another putative link between PGR5 and redox regulation involving calcium-signaling.

Moreover, N- and S- metabolisms of hpm91 were enhanced during sustained $\mathrm{H}_{2}$ photoproduction. Apart from compromised carbon metabolism in hpm91 mentioned above, we observed marked proteomic alterations in its $\mathrm{N}$ - and S-metabolic pathways during $\mathrm{H}_{2}$ production process. Considering that glutamine and glutamate are the major intracellular amino group donors for the synthesis of several other amino acids and nitrogen-containing compounds including purine and pyrimidine nucleobases (Zhang et al., 2018), we combined the functional groups of 'amino acid pathways', 'terpenoid- and de novo biosynthesis of pyrimidine nucleobase' (Fig. 4A) and referred as nitrogen metabolism in Table S3. In contrast to wild type, 3 proteins involved in 
nitrogen metabolism were only accumulated in hpm91 under sulfur deprivation. These were aspartate aminotransferase AST3, glutamate dehydrogenase GDH and GDH2, showing upto 2.20-, 13.42- and 24.56-fold increase relative to their intial levels (SI Appendix, Table S3). The former (AST3) is known to be one of the major enzymes catalyzing conversion of glutamate and oxaloacetic acid (OAA) into asparate and 2oxoglutarate (2-OG, also called alpha-KG), an intermediate of the TCA cycle (Ohashi et al., 2011) that serves as the metabolic basis for coupling $\mathrm{N}$-and $\mathrm{C}$ - metabolisms in the organisms. Because AST3 was already higher-expressed in hpm91 under normal condition (Table 1), the continued increase may strongly indicate its dominant role in asparate biosynthesis and/or maintenance of $\mathrm{C} / \mathrm{N}$ balance in the PGR5-deficient hpm91 mutant during prolonged $\mathrm{H}_{2}$ production.

More strikingly, we found marked accumulation of the latter two glutamate dehydrogenases (GDH and GDH2) in hpm91 during sustained $\mathrm{H}_{2}$ production. These proteins are supposed to play an anaplerotic role in ammonium assimilation via conversion of Glu into 2-oxoglutarate (2-OG) and ammonium in Chlamydomonas (Moyano et al., 1995). Their remarkable increase exclusively observed in hpm91 may implicate activation of this minor pathway of ammonium assimilation in the mutant under such conditions. Together with upregulation of NADH-dependent glutamate synthase GSN1 (SI Appendix, Table S3), the key enzyme of the major route GSGOGAT cycle, we propose that, due to loss of PGR5, both the major and minor route of ammonium assimilation was operational in $h p m 91$ toward sulfur-deprived $\mathrm{H}_{2}$ photoproduction. It is generally known that enhanced ammonium assimilation requires higher demand of the carbon skeleton 2-oxoglutarate (Ohashi et al., 2011) for coupling between nitrogen and carbon metabolism (Zhang et al., 2018). By activating their anaplerotic role of the glutamate dehydrogenases toward producing more 2oxoglutarate, carbon and nitrogen metabolism could be better coupled in the mutant cells than wild type under such conditions.

Regarding to S-metabolism, our results revealed remarkable accumulations for 5 key proteins involved in sulfur assimilation in hpm91 during prolonged $\mathrm{H}_{2}$ production (SI Appendix, Table S3). These include not only adenylylphosphosulfate reductase 
APR1 showing continued increase in abundance (Table 1 and SI Appendix, Table S3) but also ATP-sulfurylases (ATS1, ATS2) as well as cysteine synthase OASTL3 towards incorporation $\mathrm{SO}_{4}{ }^{2+}$ into cysteine (Gonzales-Ballester and Grossman, 2009). Because the latter two proteins were found lower-expressed in hpm91 under normal condition (Table 1), their marked accumulation as well as ATS1 during prolonged $\mathrm{H}_{2}$ production could be strongly indicating activation of the pathway towards cysteine biosynthesis (Fig. 4B, downright pannel). On the other hand, we observed upto 4.5fold accumulation of APK1 in hpm91 (SI Appendix, Table S3), implicating the sulfurassimilation pathway toward sulfation of metabolites (sulfur-containing lipids, proteins and polysaccharides (Gonzales-Ballester and Grossman, 2009) was also activated in hpm91 under such condition (Fig. 4B, downright panel). Consequently, overall sulfur assmilation was more enhanced in $h p m 91$ relative to wild type in the period of $\mathrm{H}_{2}$ photoproduction.

\section{Creating mutants with $\mathrm{H}_{2}$ production excess to $\mathrm{hpm} 91$}

As the picture of hpm91 emerges as better suited for sulfur-deprived anaerobic condition photosynthetically, metabolically and redox poisingly, we then tested a possibility of creating new strains with $\mathrm{H}_{2}$ production excess to hpm91. Fig. 5A shows a schematic diagram of the protocol tested in this work. An insertion mutant library derived from hpm91 was constructed according to (Kindle, 1990; Zhao et al., 2017) followed by tranformants selection via zeocin resistance. Since increased stability of PSII is essential to sustain sufur-deprived $\mathrm{H}_{2}$ photoproduction in Chlamydomonas (Chen et al., 2016; 2019; Volgusheva et al., 2013), we applied a two-step mutant screening, i. e. Y(II) measurements using Maxi-Imaging PAM chlorophyll fluorometer (Walz, Germany) as the first followed by $\mathrm{H}_{2}$-generating phenotype confirmation by GC analysis as described (Chen et al., 2016; 2019; Sun et al., 2013). Preliminary mutant screening identified more than two hundred transformants with $10 \%$ increase of $\mathrm{Y}$ (II) values than hpm91. Subsequent screening by GC analysis identified one of the mutants, named hpm91-108, with significantly higher $\mathrm{H}_{2}$ production than hpm91 (Fig. 5B). At $120 \mathrm{~h}, \mathrm{H}_{2}$ production in hpm91-108 was 55. 9\% 
higher than hpm91. This result is the direct experimental evidence of our previous propose (Chen et al., 2016; 2019) that hpm91 is a valuable strain for re-engineering the organism towards algal- $\mathrm{H}_{2}$ photoproduction.

\section{Concluding remarks}

In conclusion, analysis of the hpm91 mutant has revealed a number of valuable properties towards development of sunlight-powered algal $\mathrm{H}_{2}$ production systems in the near future. First, it is largely up-scalable using the 'two-step' protocol of $\mathrm{H}_{2}$ induction by sulfur deprivation (Melis et al., 2000). In the both steps, up to 100-fold extention of PBR (10 L, mixotrophic growth) (Chen et al., 2019) and HPBR (10 L, sulfur-deprived $\mathrm{H}_{2}$ photoproduction) was achieved in the laboratory set-ups, leading to an average $\mathrm{H}_{2}$ output of $7287 \mathrm{ml} / 10 \mathrm{~L}-\mathrm{HPBR}$ around 26 days. Second, hpm91 is robust during prolonged $\mathrm{H}_{2}$ production. In the absence of PGR5, hpm91 shows competent viability than wild type and remains active over a long period of sulfur deprivation, most likely due to a decrease of intracellular ROS. Third, proteome of hpm9l was modified metabolically (reinforced anti-ROS systems, compromised carbon metabolism, activation of anaplerotic route of ammonium assimilation and enhanced sulfur assmilation) and photosynthetically (optimal structure and function of PSII and PSI, reduced size of PSI antenna and CEF) towards sustained sulfur-deprived $\mathrm{H}_{2}$ photoproduction. Together with the successful isolation of new strain(s) with enhanced $\mathrm{H}_{2}$ capability relative to $h p m 91$, we highlight that this mutant strain is not only scalable but also valuable in both basic and applied research aiming at elucidating molecular regulation mechanisms of $\mathrm{H}_{2}$ metabolism in the organism and developing advanced algal- $\mathrm{H}_{2}$ production biotechnology.

\section{Materials and methods}

\section{Algal cultivation and $\mathrm{H}_{2}$ photoproduction}

Wild-type Chlamydomonas strain CC400 was purchased from the Chlamydomonas

Center (www.Chlamy.org) and the mutant strain hpm91 was isolated in our laboratory 
and reported previously (Chen et al., 2016; 2019). Genetic analysis and phenotypic rescue of several fully complemented stains as well as immunoblot detection suggest that the loss of $P G R 5$ gene is responsible for the $\mathrm{H}_{2}$-overproduing phenotype of hpm91 (Chen et al., 2016).

$\mathrm{H}_{2}$ production was induced using sulfur-deprivation method developed by Melis et al. (Melis et al., 2000) with minor modifications (Chen et al., 2010; Sun et al., 2013). Algal cells were grown in TAP medium (Gorman and Levine, 1965) at $25^{\circ} \mathrm{C}$ under continuous light $\left(60 \mu \mathrm{E} \mathrm{m}^{-2} \mathrm{~s}^{-1}\right)$ until mid-exponential phase. Cells were pelleted and washed once with sulfur-depleted TAP medium followed by resuspending in the medium with desired cell density of 20 - (for 10L-HPBR) and $25 \mu \mathrm{g} \mathrm{ml}^{-1}$ chlorophyll ( $a$ and $b$ ) (Arnon, 1949), respectively. $\mathrm{H}_{2}$ evolution was achieved via transferring the culture into small $\mathrm{H}_{2}$ photobioreactor $(100 \mathrm{ml})$ for biochemical analysis and large gastight glass bottles (large-HPBR, upto $10 \mathrm{~L}$ ) connected by a Teflon tube to storage glass cylinder for scaling-up studies followed by magnetic-bar-stiring cultivation at the same condition mentioned above (for small-HPBR) or upto $230 \mu \mathrm{E} \mathrm{m}^{-2} \mathrm{~s}^{-1}$ (for large HPBR), respectively. $\mathrm{H}_{2}$ gas accumulated in the headspace of the small HPBR was measured by gas chromatograph (GC-2014, Shimadzu, Japan) as previously (Chen et al., 2016; 2019; Sun et al., 2013; Zhao et al., 2013). The evolved $\mathrm{H}_{2}$ gas from the headspace of large HPBR was collected in inverted graduated cylinders and measured by the displacement of water (Chen et al., 2010).

\section{Intracellular ROS and cell growth analysis}

Intracellular ROS content was determined using a MoFlo XDP high-speed flow cytometer (Beckman-Coulter, Inc. USA) by following the manufacturer's instructions. Samples were prepared in an anoxia workstation (Longyao, LAI-3T; Shanghai, China) as (Chen et al., 2019). Cells were incubated with $10 \mathrm{mM} \mathrm{H}_{2} \mathrm{DCFDA}$ at $25^{\circ} \mathrm{C}$ for 30 min in dark then examined by the flow cytometer. For detection of DCF green fluorescence, wavelength of excitation at $488 \mathrm{~nm}$ and emission at 510 to $550 \mathrm{~nm}$ was used. Rosup provided by a ROS assay kit (Beyotime Institute of Biotechnology, Haimen, China) was used as a positive control. Average fluorescence intensity of 
DCF from $3 \times 10^{5}$ cells was recorded and data acquisition and analysis were carried out using Summit 5.2 software (Beckman-Coulter, Inc. USA). Morphology of algal cells was examined and photographed with a differential interference contrast microscopy (DIC) (Leica DM4500, Germany). Culture density were determined by cell counting using a hemocytometer.

\section{iTRAQ proteomics and data analysis}

Protein extraction and sample preparation for iTRAQ labeling was done as described (Chen et al., 2010) with minor modifications (Ge et al., 2017). Frozen cells suspended in ice-cold extraction buffer were disrupted with glass beads (diameter 150-212 $\mu \mathrm{m}$, Sigma) via vortexing $30 \mathrm{~s} / 5$ cycles/each with 1-min break on ice. After removed unbroken cells and insoluble debris, total proteins in the supernatant were precipitated with ice-cold $10 \%$ trichloroacetic acid (TCA) in acetone at $-20^{\circ} \mathrm{C}$. Protein pellets were washed with acetone by centrifugation and vacuum-dried. The proteins were resolubilized with $4 \%$ sodium dodecyl sulfate (SDS) in $0.1 \mathrm{M}$ Tris- $\mathrm{HCl}, \mathrm{pH}$ 7.6. Protein concentration was determined using BCA protein assay kit (Thermo Scientific, Rockford, IL).

Trypsin digestion of proteins was perfomed using the filter-aided sample preparation (FASP) method with slight modifications (Wisniewski et al., 2009). The resulting tryptic peptides were labeled with 8-plex iTRAQ reagents (AB Sciex Inc., MA, USA) alternatively by following manufacturer's manual. The iTRAQ labeled samples were mixed together with equal ratios in amount, and the mixture was concentrated with a SpeedVac in subjection for fractionation by HPLC (Waters, e2695 separations) coupled with a phenomenex gemini-NX 5u C18 column $(250 \times 3.0 \mathrm{~mm}$, $110 \AA$ A) (Torrance, CA, USA). The samples were then separated using a 97 min basic RP-LC gradient as described (Udeshi et al., 2013) and a flow rate of $0.4 \mathrm{~mL} / \mathrm{min}$ was used. The separated samples were collected into 10 fractions and vacuum-dried prior to LC-MS/MS analysis by a TripleTOF 5600 mass spectrometer (AB SCIEX) coupled online to an Eksigent nanoLC Ultra in Information Dependent Mode. Peptides were separated on a C18 column (Acclaim PepMap C18, 250 mm x $75 \mu \mathrm{m}$ x $5 \mu \mathrm{m}, 100 \AA$, 
Dionex) with a 90 min nonlinear gradient of buffer B (100\% ACN, 0.1\% FA) from $3 \%$ to $30 \%$. The gradient was set as $3 \%-8 \%$ B for $10 \mathrm{~min}, 8 \%-20 \%$ B for $60 \mathrm{~min}$, $20 \%-30 \%$ B for $8 \mathrm{~min}, 30 \%-100 \%$ B for $2 \mathrm{~min}$, and $100 \%$ B for $10 \mathrm{~min}$ at a flow rate of $300 \mathrm{nl} / \mathrm{min}$. MS spectra survey scan was done across mass range of 350 to 1500 $\mathrm{m} / \mathrm{z}$ and the spectra data were acquired at resolution 30000 with $250 \mathrm{~ms}$ accumulation per spectrum. 25 most intense ions from each MS scan were chosen for fragmentation from each MS spectrum with $2 \mathrm{sec}$ minimum accumulation time for each precursor and dynamic exclusion for $18 \mathrm{sec}$. Tandem mass spectra were recorded in high sensitivity mode (resolution >15000) with rolling collision energy on and iTRAQ reagent collision energy adjustment on.

Peptide and protein identification and quantification was performed with the ProteinPilot 4.5 software (AB SCIEX) using the Paragon database search algorithm. The Chlamydomonas proteome sequences downloaded from UniProt (dated 2-072016) were used for the database searching with manual editing using the information (updated on 11-12-2019) in Uniprot database. The false discovery rate (FDR) analysis was performed using the software PSPEP integrated with the ProteinPilot. Confidence of quantitation for differentially expressed proteins was analyzed with the ProteinPilot Descriptive Statistics Template (PDST) (beta v3.07p, AB SCIEX). Gene ontology (GO) enrichment analysis of proteins was performed using DAVID Bioinformatic Resources 6.8 (https://david.ncifcrf.gov/summary.jsp) with the following parameters: 'Gene List Enrichment', 'Chlamydomonas reinhardtii species', 'Uniprot Accession'. Functional annotation and classification of the differentially expressed proteins was mainly based on the search results of 'Biological processes' in DAVID analysis followed by manual editing using the updated Chlamydomonas genome data in NCBI (updated on 30-01-2018). Differentially expressed proteins were selected with $p$ value $<0.05$ and cut-off $>1.2$ and $<0.83$ as up-and down-regulated, respectively.

\section{Generation and screening of hpm91-derived mutants}

Insertion mutant library was constructed by transformation of hpm 91 using the glass bead method with KpnI-linearized plasmid pDble containing the ble gene conferring 
zeocin resistance (Kindle, 1990). Transformants growing on TAP plates with $10 \mu \mathrm{g}$ $\mathrm{mL}^{-1}$ zeocin (Solarbio) were isolated. After cultured on TAP-S plates for one week, mutants were screened based on increased Y(II) values relative to hpm91 using MaxiImaging PAM chlorophyll fluorometer (Walz, Germany) as previously (Zhao et al., 2017) followed by $\mathrm{H}_{2}$ measurements by GC analysis (Chen et al., 2019; Sun et al., 2013).

Data availability: All data needed to evaluate conclusions of this paper are present in the paper and in SI Appendix.

Acknowledgements: This work was supported by funding from the National Natural Science Foundation of China (31470340), the Ministry of Science and Technology of China (2015CB150100) and CAS (XDB17030300, KGCX2-YW-373).

Author contributions: M.C., Y.W. and F.H. conceived the project and designed the research; P.L., D.Y., M.C., J.Z., L.S. and X.H. carried out the experiments and data analysis; X. X., K. X., Y.Y. and Y. G. performed genomic sequencing and data analysis; P.L. and D.Y. prepared data files; P.L., D.Y., Y.W. and F.H. wrote the manuscript, with input from all authors. All authors approved the final manuscript.

Competing interests: The authors declare no competing interests. This work is included in a patent application by Institute of Botany, Chinese Academy of Sciences. The patent 202110779011.4 covers a method of application.

\section{References}

Arnon, D.I. (1949). Copper enzymes in isolated chloroplasts. polyphenoloxidase in Beta vulgaris. Plant Physiol. 24, 1-15. https://doi.org/10.1104/pp.24.1.1.

Bayro-Kaiser, V., and Nelson, N. (2017). Microalgal hydrogen production: prospects of an essential technology for a clean and sustainable energy economy. Photosynth. Res. 133, 49-62. https://doi.org/10.1007/s11120-017-0350-6.

Chen F., Y.L., Yang, F., Wang, L., Guo, X.Q., Gao, F., Hua, C., Tan, C., Fang, L., Shan, R.Q., Zeng, W.J., Wang, B., Wang, R., Xu, X., Wei, X.F. (2020). CNGBdb: China National GeneBank DataBase. Hereditas(Beijing) 42, 799-809. https://doi.org/10.16288/j.yczz.20-080.

Chen, M., Liu, P., Zhang, F., Peng, L.W., and Huang, F. (2019). Photochemical 
characteristics of Chlamydomonas mutant hpm91 lacking proton gradient regulation 5 (PGR5) during sustained $\mathrm{H}_{2}$ photoproduction under sulfur deprivation. Int. J. Hydrogen Energ. 44, 31790-31799. https://doi.org/10.1016/j.ijhydene.2019.10.074.

Chen, M., Zhang, J., Zhao, L., Xing, J., Peng, L., Kuang, T., Rochaix, J.D., and Huang, F. (2016). Loss of algal proton gradient regulation 5 increases reactive oxygen species scavenging and $\mathrm{H}_{2}$ evolution. J. Integr. Plant Biol. 58, 943-946. https://doi.org/10.1111/jipb.12502.

Chen, M., Zhao, K., Sun, Y.L., Cui, S.X., Zhang, L.F., Yang, B., Wang, J., Kuang, T.Y., and Huang, F. (2010). Proteomic analysis of hydrogen photoproduction in sulfurdeprived Chlamydomonas cells. J. Proteome Res. 9, 3854-3866. https://doi.org/10.1021/pr100076c.

Chen, Y., Chen, Y., Shi, C., Huang, Z., Zhang, Y., Li, S., Li, Y., Ye, J., Yu, C., Li, Z., et al. (2018). SOAPnuke: a MapReduce acceleration-supported software for integrated quality control and preprocessing of high-throughput sequencing data. Gigascience 7, 1-6. https://doi.org/10.1093/gigascience/gix120.

Day, I.S., Reddy, V.S., Shad Ali, G., and Reddy, A.S. (2002). Analysis of EF-handcontaining proteins in Arabidopsis. Genome Biol. 3, RESEARCH0056.1. https://doi.org/10.1186/gb-2002-3-10-research0056.

Forestier, M., King, P., Zhang, L.P., Posewitz, M., Schwarzer, S., Happe, T., Ghirardi, M.L., and Seibert, M. (2003). Expression of two [Fe]-hydrogenases in Chlamydomonas reinhardtii under anaerobic conditions. Eur. J. Biochem. 270, 27502758. https://doi.org/10.1046/j.1432-1033.2003.03656.

Ge, H.T., Fang, L.F., Huang, X.H., Wang, J.L., Chen, W.Y., Liu, Y., Zhang, Y.Y., Wang, X.R., Xu, W., He, Q.F., and Wang, Y.C. (2017). Translating divergent environmental stresses into a common proteome response through the histidine kinase 33 (Hik33) in a model Cyanobacterium. Mol. Cell Proteomics 16, 1258-1274. https://doi.org/10.1074/mcp.M116.068080

Gfeller, R.P., and Gibbs, M. (1984). Fermentative metabolism of Chlamydomonas reinhardtii 1: I. analysis of fermentative products from starch in dark and light. Plant Physiol. 75, 212-218. https://doi.org/10.1104/pp.75.1.212.

Ghirardi, M.L. (2015). Implementation of photobiological $\mathrm{H}_{2}$ production: the $\mathrm{O}_{2}$ sensitivity of hydrogenases. Photosynth. Res. 125, 383-393. https://doi.org/10.1007/s11120-015-0158-1.

Gonzales-Ballester, D., and Grossman, A.R. (2009). Sulfur: From acquisition to assimilation. In The Chlamydomonas Sourcebook Second Edition, D.B. Stern, ed. (Elsevier), pp. 159-187.

Gorman, D.S., and Levine, R.P. (1965). Cytochrome f and plastocyanin - their sequence in photosynthetic electron transport chain of Chlamydomonas reinhardi. Proc. Natl. Acad. Sci. U.S.A. 54, 1665-1669. https://doi.org/10.1073/pnas.54.6.1665. Greenbaum, E. (1988). Energetic efficiency of hydrogen photoevolution by algal water splitting. Biophys. J. 54, 365-368. https://doi.org/10.1016/S00063495(88)82968-0.

Guo, X.Q., Chen, F.Z., Gao, F., Li, L., Liu, K., You, L.J., Hua, C., Yang, F., Liu, W.L., Peng, C.H., et al. (2020). CNSA: a data repository for archiving omics data. Database 
2020, baaa055

https://doi.org/10.1093/database/baaa055.

GutierrezMarcos, J.F., Roberts, M.A., Campbell, E.I., and Wray, J.L. (1996). Three members of a novel small gene-family from Arabidopsis thaliana able to complement functionally an Escherichia coli mutant defective in PAPS reductase activity encode proteins with a thioredoxin-like domain and "APS reductase" activity. Proc. Natl. Acad. Sci. U.S.A. 93, 13377-13382. https://doi.org/10.1073/pnas.93.23.13377.

Haber, Z., Lampl, N., Meyer, A.J., Zelinger, E., Hipsch, M., and Rosenwasser, S. (2021). Resolving diurnal dynamics of the chloroplastic glutathione redox state in Arabidopsis reveals its photosynthetically derived oxidation. Plant Cell 33, 1828-1844. https://doi.org/10.1093/plcell/koab068.

Hemschemeier, A., Melis, A., and Happe, T. (2009). Analytical approaches to photobiological hydrogen production in unicellular green algae. Photosynth. Res. 102, 523-540. https://doi.org/10.1007/s11120-009-9415-5.

Iwai, M., Takizawa, K., Tokutsu, R., Okamuro, A., Takahashi, Y., and Minagawa, J. (2010). Isolation of the elusive supercomplex that drives cyclic electron flow in photosynthesis. Nature 464, 1210-1213. https://doi.org/10.1038/nature08885.

Johnson, X., Steinbeck, J., Dent, R.M., Takahashi, H., Richaud, P., Ozawa, S.I., Houille-Vernes, L., Petroutsos, D., Rappaport, F., Grossman, A.R., et al. (2014). Proton gradient regulation 5-mediated cyclic electron flow under ATP- or redoxlimited conditions: A study of $\triangle \mathrm{ATPase}$ pgr5 and $\Delta \mathrm{rbcL}$ pgr5 mutants in the green alga Chlamydomonas reinhardtii. Plant Physiol. 165, 438-452. https://doi.org/10.1104/pp.113.233593.

Kawasaki, H., and Kretsinger, R.H. (2017). Structural and functional diversity of EFhand proteins: Evolutionary perspectives. Protein Sci. 26, 1898-1920. https://doi.org/10.1002/pro.3233.

Kindle, K.L. (1990). High-Frequency nuclear transformation of Chlamydomonas reinhardtii. Proc. Natl. Acad. Sci. U.S.A. 87, 1228-1232. https://doi.org/10.1073/pnas.87.3.1228.

Kosourov, S., Tsygankov, A., Seibert, M., and Ghirardi, M.L. (2002). Sustained hydrogen photoproduction by Chlamydomonas reinhardtii: Effects of culture parameters. Biotechnol. Bioeng 78, 731-740. https://doi.org/10.1002/bit.10254.

Kosourov, S.N., Ghirardi, M.L., and Seibert, M. (2011). A truncated antenna mutant of Chlamydomonas reinhardtii can produce more hydrogen than the parental strain. Int. J. Hydrogen Energ. 36, 2044-2048. https://doi.org/10.1016/j.ijhydene.2010.10.041.

Kruse, O., Rupprecht, J., Bader, K.P., Thomas-Hall, S., Schenk, P.M., Finazzi, G., and Hankamer, B. (2005). Improved photobiological $\mathrm{H}_{2}$ production in engineered green algal cells. J. Biol. Chem. 280, 34170-34177. https://doi.org/10.1074/jbc.M503840200.

Li, H. (2013). Aligning sequence reads, clone sequences and assembly contigs with BWA-MEM. arXiv:1303.3997. https://doi.org/10.6084/M9.FIGSHARE.963153.V1.

Lu, Y., Gan, Q., Iwai, M., Alboresi, A., Burlacot, A., Dautermann, O., Takahashi, H., Crisanto, T., Peltier, G., Morosinotto, T., et al. (2021). Role of an ancient light- 
harvesting protein of PSI in light absorption and photoprotection. Nat. Commun. 12, 679. https://doi.org/10.1038/s41467-021-20967-1.

Merchant, S.S., Prochnik, S.E., Vallon, O., Harris, E.H., Karpowicz, S.J., Witman, G.B., Terry, A., Salamov, A., Fritz-Laylin, L.K., Marechal-Drouard, L., et al. (2007). The Chlamydomonas genome reveals the evolution of key animal and plant functions. Science 318, 245-251. https://doi.org/10.1126/science.1143609.

Melis, A., Zhang, L.P., Forestier, M., Ghirardi, M.L., and Seibert, M. (2000). Sustained photobiological hydrogen gas production upon reversible inactivation of oxygen evolution in the green alga Chlamydomonas reinhardtii. Plant Physiol. 122, 127-135. https://doi.org/10.1104/pp.122.1.127.

Moyano, E., Cardenas, J., and Munozblanco, J. (1995). Involvement of NAD(P) ${ }^{+}$ glutamate dehydrogenase isoenzymes in carbon and nitrogen metabolism in Chlamydomonas reinhardtii. Physiol. Plantarum 94, 553-559. https://doi.org/10.1034/j.1399-3054.1995.940403.x.

Munekage, Y., Hojo, M., Meurer, J., Endo, T., Tasaka, M., and Shikanai, T. (2002). PGR5 is involved in cyclic electron flow around photosystem I and is essential for photoprotection in Arabidopsis. Cell 110, 361-371. https://doi.org/10.1016/S0092$\underline{\text { 8674(02)00867-X. }}$.

Nishiyama, H., Yamada, T., Nakabayashi, M., Maehara, Y., Yamaguchi, M., Kuromiya, Y., Nagatsuma, Y., Tokudome, H., Akiyama, S., Watanabe, T., et al. (2021). Photocatalytic solar hydrogen production from water on a $100-\mathrm{m}^{2}$ scale. Nature 598 , 304-307. https://doi.org/10.1038/s41586-021-03907-3.

Ohashi, Y., Shi, W., Takatani, N., Aichi, M., Maeda, S., Watanabe, S., Yoshikawa, H., and Omata, T. (2011). Regulation of nitrate assimilation in cyanobacteria. J. Exp. Bot. 62, 1411-1424. https://doi.org/10.1093/jxb/erq427.

Philipps, G., Krawietz, D., Hemschemeier, A., and Happe, T. (2011). A pyruvate formate lyase-deficient Chlamydomonas reinhardtii strain provides evidence for a link between fermentation and hydrogen production in green algae. Plant J. 66, 330-340. https://doi.org/10.1111/j.1365-313X.2011.04494.x.

Ravina, C.G., Chang, C.I., Tsakraklides, G.P., McDermott, J.P., Vega, J.M., Leustek, T., Gotor, C., and Davies, J.P. (2002). The sac mutants of Chlamydomonas reinhardtii reveal transcriptional and posttranscriptional control of cysteine biosynthesis. Plant Physiol. 130, 2076-2084. https://doi.org/10.1104/pp.012484.

Schonfeld, C., Wobbe, L., Borgstadt, R., Kienast, A., Nixon, P.J., and Kruse, O. (2004). The nucleus-encoded protein MOC1 is essential for mitochondrial light acclimation in Chlamydomonas reinhardtii. J. Biol. Chem. 279, 50366-50374. https://doi.org/10.1074/jbc.M408477200.

Schwenkert, S., Fernie, A.R., Geigenberger, P., Leister, D., Mohlmann, T., Naranjo, B., and Neuhaus, H.E. (2022). Chloroplasts are key players to cope with light and temperature stress. Trends Plant Sci. https://doi.org/10.1016/j.tplants.2021.12.004.

Scoma, A., Krawietz, D., Faraloni, C., Giannelli, L., Happe, T., and Torzillo, G. (2012). Sustained $\mathrm{H}_{2}$ production in a Chlamydomonas reinhardtii D1 protein mutant. J. Biotechnol. 157, 613-619. https://doi.org/10.1016/j.jbiotec.2011.06.019.

Setya, A., Murillo, M., and Leustek, T. (1996). Sulfate reduction in higher plants: 
Molecular evidence for a novel 5'-adenylylsulfate reductase. Proc. Natl. Acad. Sci. U.S.A. 93, 13383-13388. https://doi.org/10.1073/pnas.93.23.13383.

Shen, J.R. (2015). The structure of Photosystem II and the mechanism of water oxidation in photosynthesis. Annu. Rev. Plant Biol. 66, 23-48. https://doi.org/10.1146/annurev-arplant-050312-120129.

Shen, L.L., Huang, Z.H., Chang, S.H., Wang, W.D., Wang, J.F., Kuang, T.Y., Han, G.Y., Shen, J.R., and Zhang, X. (2019). Structure of a $\mathrm{C}_{2} \mathrm{~S}_{2} \mathrm{M}_{2} \mathrm{~N}_{2}$ type PSII-LHCII supercomplex from the green alga Chlamydomonas reinhardtii. Proc. Natl. Acad. Sci. U.S.A. 116, 21246-21255. https://doi.org/10.1073/pnas.1912462116.

Steinbeck, J., Nikolova, D., Weingarten, R., Johnson, X., Richaud, P., Peltier, G., Hermann, M., Magneschi, L., and Hippler, M. (2015). Deletion of proton gradient regulation 5 (PGR5) and PGR5-like 1 (PGRL1) proteins promote sustainable lightdriven hydrogen production in Chlamydomonas reinhardtii due to increased PSII activity under sulfur deprivation. Front. Plant Sci. 6. 892 https://doi.org/10.3389/fpls.2015.00892.

Su, X.D., Ma, J., Pan, X.W., Zhao, X.L., Chang, W.R., Liu, Z.F., Zhang, X.Z., and Li, M. (2019). Antenna arrangement and energy transfer pathways of a green algal photosystem-I-LHCI supercomplex. Nat. Plants 5, 273-281. https://doi.org/10.1038/s41477-019-0380-5.

Suga, M., Ozawa, S.I., Yoshida-Motomura, K., Akita, F., Miyazaki, N., and Takahashi, Y. (2019). Structure of the green algal photosystem I supercomplex with a decameric light-harvesting complex I. Nat. Plants 5, 626-636. https://doi.org/10.1038/s41477019-0438-4.

Sun, Y.L., Chen, M., Yang, H.M., Zhang, J., Kuang, T.Y., and Huang, F. (2013). Enhanced $\mathrm{H}_{2}$ photoproduction by down-regulation of ferredoxin-NADP ${ }^{+}$reductase (FNR) in the green alga Chlamydomonas reinhardtii. Int. J. Hydrogen Energ. 38, 16029-16037. https://doi.org/10.1016/j.ijhydene.2013.10.011.

Suorsa, M., Jarvi, S., Grieco, M., Nurmi, M., Pietrzykowska, M., Rantala, M., Kangasjarvi, S., Paakkarinen, V., Tikkanen, M., Jansson, S., and Aro, E.M. (2012). Proton gradient regulation5 is essential for proper acclimation of arabidopsis photosystem I to naturally and artificially fluctuating light conditions. Plant Cell 24, 2934-2948. https://doi.org/10.1105/tpc.112.097162.

Takahashi, H., Clowez, S., Wollman, F.A., Vallon, O., and Rappaport, F. (2013). Cyclic electron flow is redox-controlled but independent of state transition. Nat. Commun. 4. 1954

https://doi.org/10.1038/ncomms2954.

Thorvaldsdottir, H., Robinson, J.T., and Mesirov, J.P. (2013). Integrative Genomics Viewer (IGV): high-performance genomics data visualization and exploration. Brief. Bioinform. 14, 178-192. https://doi.org/10.1093/bib/bbs017.

Tolleter, D., Ghysels, B., Alric, J., Petroutsos, D., Tolstygina, I., Krawietz, D., Happe, T., Auroy, P., Adriano, J.M., Beyly, A., et al. (2011). Control of hydrogen photoproduction by the proton gradient generated by cyclic electron flow in Chlamydomonas reinhardtii. Plant Cell 23, 2619-2630. https://doi.org/10.1105/tpc.111.086876. 
Trosch, R., Barahimipour, R., Gao, Y., Badillo-Corona, J.A., Gotsmann, V.L., Zimmer, D., Muhlhaus, T., Zoschke, R., and Willmund, F. (2018). Commonalities and differences of chloroplast translation in a green alga and land plants. Nat. Plants 4 , 564-575. https://doi.org/10.1038/s41477-018-0211-0.

Udeshi, N.D., Svinkina, T., Mertins, P., Kuhn, E., Mani, D.R., Qiao, J.W., and Carr, S.A. (2013). Refined preparation and use of anti-diglycine remnant (K-epsilon-GG) antibody enables routine quantification of 10,000 s of ubiquitination sites in single proteomics experiments. Mol. Cell Proteomics 12, 825-831. https://doi.org/10.1074/mcp.O112.027094.

Umena, Y., Kawakami, K., Shen, J.R., and Kamiya, N. (2011). Crystal structure of oxygen-evolving photosystem II at a resolution of 1.9 angstrom. Nature 473, 55-60. https://doi.org/10.1038/nature09913.

Volgusheva, A., Styring, S., and Mamedov, F. (2013). Increased photosystem II stability promotes $\mathrm{H}_{2}$ production in sulfur-deprived Chlamydomonas reinhardtii. Proc. Natl. Acad. Sci. U. S. A. 110, 7223-7228. https://doi.org/10.1073/pnas.1220645110.

Wang, H., Alvarez, S., and Hicks, L.M. (2012). Comprehensive comparison of iTRAQ and label-free LC-based quantitative proteomics approaches using two Chlamydomonas reinhardtii strains of interest for biofuels engineering. J. Proteome Res. 11, 487-501. https://doi.org/10.1021/pr2008225.

Weigelt, K., Kuster, H., Rutten, T., Fait, A., Fernie, A.R., Miersch, O., Wasternack, C., Emery, R.J.N., Desel, C., Hosein, F., et al. (2009). ADP-glucose pyrophosphorylasedeficient pea embryos reveal specific transcriptional and metabolic changes of carbon-nitrogen metabolism and stress responses. Plant Physiol. 149, 395-411. https://doi.org/10.1104/pp.108.129940.

Wisniewski, J.R., Zougman, A., Nagaraj, N., and Mann, M. (2009). Universal sample preparation method for proteome analysis. Nat. Methods 6, 359-362. https://doi.org/10.1038/nmeth.1322

Yacoby, I., Pochekailov, S., Toporik, H., Ghirardi, M.L., King, P.W., and Zhang, S.G. (2011). Photosynthetic electron partitioning between [FeFe]-hydrogenase and ferredoxin:NADP ${ }^{+}$-oxidoreductase (FNR) enzymes in vitro. Proc. Natl. Acad. Sci. U. S. A. 108, 9396-9401. https://doi.org/10.1073/pnas.1103659108.

Yang, W.Q., Catalanotti, C., Wittkopp, T.M., Posewitz, M.C., and Grossman, A.R. (2015). Algae after dark: mechanisms to cope with anoxic/hypoxic conditions. Plant J. 82, 481-503. https://doi.org/10.1111/tpj.12823.

Zhang, C.C., Zhou, C.Z., Burnap, R.L., and Peng, L. (2018). Carbon/Nitrogen metabolic balance: Lessons from Cyanobacteria. Trends Plant Sci. 23, 1116-1130. https://doi.org/10.1016/j.tplants.2018.09.008.

Zhang, L.P., Happe, T., and Melis, A. (2002). Biochemical and morphological characterization of sulfur-deprived and $\mathrm{H}_{2}$-producing Chlamydomonas reinhardtii (green alga). Planta 214, 552-561. https://doi.org/10.1007/s004250100660.

Zhang, Z.D., Shrager, J., Jain, M., Chang, C.W., Vallon, O., and Grossman, A.R. (2004). Insights into the survival of Chlamydomonas reinhardtii during sulfur starvation based on microarray analysis of gene expression. Eukaryot. Cell 3, 13311348. https://doi.org/10.1128/Ec.3.5.1331-1348.2004. 
Zhao, L., Chen, M., Cheng, D.M., Yang, H.M., Sun, Y.L., Zhou, H.Y., and Huang, F. (2013). Different B-Type Methionine Sulfoxide Reductases in Chlamydomonas May Protect the Alga against High-Light, Sulfur-Depletion, or Oxidative Stress. J. Integr. Plant Biol. 55, 1054-1068. https://doi.org/10.1111/jipb.12104.

Zhao, L., Cheng, D.M., Huang, X.H., Chen, M., Dall'Osto, L., Xing, J.L., Gao, L.Y., Li, L.Y., Wang, Y., Bassi, R., et al. (2017). A light harvesting complex- like protein in maintenance of photosynthetic components in Chlamydomonas. Plant Physiol. 174, 2419-2433. https://doi.org/10.1104/pp.16.01465.

\section{Figure legends}

Fig. 1. $\mathrm{H}_{2}$ production of hpm91 in 1 to $10 \mathrm{~L}-\mathrm{HPBR}$ under sulfur deprivation. (A) Photograph of 1 to $3 \mathrm{~L}-H P B R$ (optical path $10 \mathrm{~cm}, 100 \mu \mathrm{E} \mathrm{m}^{-2} \mathrm{~s}^{-1}$.) taken at 10 day of sulfur deprivation. (B) Correlation between $\mathrm{H}_{2}$ output and size of HPBR. Standard deviations were estimated from three biological replicates. $(C)$ Photograph of wild type and hpm91 in 10L-HPBR taken at 4 day of sulfur deprivation. (D) Comparison of $\mathrm{H}_{2}$ output profiles of hpm91 in 10L-HPBR under light intensity of 130 (in black) and $230 \mu \mathrm{E} \mathrm{m}^{-2} \mathrm{~s}^{-1}$ (in red). The data are from three independent experiments.

Fig. 2. Comparison of intracellular ROS contents of hpm91 and wild type during 120 h of sulfur-deprived $\mathrm{H}_{2}$ production process. (A) and (B) Cell morphology and proliferation of the two strains. $(C)$ and $(D)$ Scatter diagram and quantification of intracellular ROS contents in the two strains. Sample preparation was performed under anoxia and ROS levels were determined using a MoFlo XDP high-speed flow cytometer (Beckman-Coulter, Inc. USA) by following the manufacturer's instructions. Average fluorescence intensity of DCF from $3 \times 10^{5}$ cells was recorded and data acquisition and analysis were carried out using Summit 5.2 software. Experiments were repeated three times with similar results. * and ** refer to p-values $<0.05$ and $<0.01$ in Student's t-test, respectively.

Fig. 3. Overview of iTRAQ proteomics of hpm9l and wild type during $120 \mathrm{~h}$ of sulfur-deprived $\mathrm{H}_{2}$ production. (A) Schematic presentation of iTRAQ experimental design. (B) Hierarchy clustering analysis showing high reproducibility of protein quantitation. (C) Number of differential expressed proteins in hpm91 and wild type using a cutoff of 1.2-fold change with significance $(\mathrm{p}<0.05)$. (D) KEGG analysis of 
group I proteins in $(C)$ showing major proteome changes caused by PGR5 deletion in Chlamydomonas.

DAVID

Bioinformatic

Resources

(https://david.ncifcrf.gov/summary.jsp) was used.

Fig. 4. Proteomic characteristics of hpm9l during sustained $\mathrm{H}_{2}$ production. (A) Comparison of GOBP enrichmemts in hpm9l and wild type during $120 \mathrm{~h}$ of sulfur seprivation. (B) Major proteome feature of hpm91 under sulfur-deprived condition. Volcano plot shows major changes in carbon metabolism of hpm91 during $120 \mathrm{~h}$ of sulfur-deprivation (upleft panel). Comparison of average fold-change of photosynthetic proteins in hpm91 and wild type at $120 \mathrm{~h}$ sulfur-deprivation (upright panel). Dynamic changes of redox proteins in hpm91 during 120 of sulfur deprivation (downleft panel). Schematic illustration of N- and S-metabolic features in hpm9l under sulfur-deprived condition (downright panel).

Fig. 5. Screening for $\mathrm{H}_{2}$-production mutants excess to hpm91. (A) Outline of the screening method. (B) Phenotype confirmation of the hpm91-derived mutants. $\mathrm{H}_{2-}$ producing capability of the selected mutants was determined with a GC-2014 gas chromatographer (Shimadzu; Japan) at 5 days of sulfur deprivation. Standard deviations were estimated from 3 biological replicates. 
Table 1. List of proteins corresponding to Fig. 3D.

\begin{tabular}{|c|c|c|c|c|c|}
\hline $\begin{array}{l}\text { KEGG } \\
\text { pathway }\end{array}$ & $\begin{array}{l}\text { Uniprot } \\
\text { accession }\end{array}$ & Gene ID & Protein name & $\begin{array}{c}\text { Ratio } \\
(\mathrm{Mu} 0 / \mathrm{Wt} 0)\end{array}$ & $\begin{array}{l}p \text {-value } \\
(<0.05)\end{array}$ \\
\hline \multirow{27}{*}{$\begin{array}{l}\text { Ribosomal } \\
\text { proteins }\end{array}$} & A8JEP1 & PRPL35 & 50S ribosomal protein L35 & 1.80 & $3.73 \mathrm{E}-02$ \\
\hline & A8IQE3 & RPL14 & Ribosomal protein L14 & 1.60 & $2.06 \mathrm{E}-02$ \\
\hline & A8J9D9 & PRPL24 & Plastid ribosomal protein L24 & 1.63 & $2.23 \mathrm{E}-03$ \\
\hline & A8JGK1 & RPS17 & Ribosomal protein $\mathrm{S} 17$ & 3.41 & $3.43 \mathrm{E}-03$ \\
\hline & A8HVP2 & RPS18 & Ribosomal protein S18 & 3.07 & 4.63E-02 \\
\hline & A8HQ81 & RPL11 & Ribosomal protein L11 & 1.42 & 3.99E-04 \\
\hline & A8JDN4 & PRPS20 & Plastid ribosomal protein S20 & 3.06 & $7.10 \mathrm{E}-03$ \\
\hline & A8J2G4 & RPL32 & Ribosomal protein L32 & 1.53 & $2.99 \mathrm{E}-02$ \\
\hline & A8HVP7 & PRPL10 & Plastid ribosomal protein L10 & 1.51 & 4.71E-02 \\
\hline & A8IVE2 & RPL7 & Ribosomal protein L7 & 2.35 & $3.00 \mathrm{E}-02$ \\
\hline & A8I0I1 & RPS24 & $40 \mathrm{~S}$ ribosomal protein $\mathrm{S} 24$ & 1.55 & $1.83 \mathrm{E}-02$ \\
\hline & A8HVK4 & RPS27a & Ribosomal protein S27a & 1.47 & $1.26 \mathrm{E}-03$ \\
\hline & A8IB25 & CHLREDRAFT_126059 & $40 \mathrm{~S}$ ribosomal protein SA & 1.44 & $1.39 \mathrm{E}-02$ \\
\hline & A8IVK1 & RPL8 & Ribosomal protein L8 & 1.97 & $3.02 \mathrm{E}-02$ \\
\hline & A8INR7 & PRPL27 & Plastid ribosomal protein L27 & 2.26 & $6.07 \mathrm{E}-03$ \\
\hline & A8ID84 & RPL3 & Ribosomal protein L3 & 1.59 & $6.87 \mathrm{E}-05$ \\
\hline & P48267 & rps7 & Chloroplastic 30S ribosomal protein S7 & 1.81 & $3.11 \mathrm{E}-02$ \\
\hline & A8HVQ1 & RPS8 & $40 \mathrm{~S}$ ribosomal protein $\mathrm{S} 8$ & 1.56 & $6.57 \mathrm{E}-03$ \\
\hline & A8JF05 & RPL28 & Ribosomal protein L28 & 1.43 & 7.34E-04 \\
\hline & P59776 & rps19 & Chloroplastic 30S ribosomal protein S19 & 1.85 & $3.56 \mathrm{E}-03$ \\
\hline & A8J4Q3 & RPS10 & Ribosomal protein S10 & 1.77 & $1.59 \mathrm{E}-02$ \\
\hline & A8J8P4 & RPL34 & Ribosomal protein L34 & 1.39 & 4.65E-02 \\
\hline & Q9GGE2 & rps14 & Chloroplastic 30S ribosomal protein S14 & 1.63 & 2.27E-02 \\
\hline & A8HMG7 & RPL26 & Ribosomal protein L26 & 1.68 & 4.19E-02 \\
\hline & A8J768 & RPS14 & Ribosomal protein $\mathrm{S} 14$ & 3.11 & $2.22 \mathrm{E}-02$ \\
\hline & A8J8M9 & RPS20 & Ribosomal protein $\mathrm{S} 20$ & 1.55 & 7.45E-03 \\
\hline & A8HS59 & RPL17 & Ribosomal protein L17 & 1.89 & $2.46 \mathrm{E}-02$ \\
\hline \multirow{13}{*}{$\begin{array}{l}\text { Photosynthesis- } \\
\text { antenna } \\
\text { proteins }\end{array}$} & Q75VY6 & LHCA6 & Light-harvesting protein of photosystem I & 0.68 & $2.93 \mathrm{E}-02$ \\
\hline & Q75VY8 & LHCA5 & Light-harvesting protein of photosystem I & 0.55 & $1.75 \mathrm{E}-05$ \\
\hline & A8J249 & LHCA1 & Light-harvesting protein of photosystem I & 0.67 & 4.09E-03 \\
\hline & A8ISG0 & LHCA7 & Light-harvesting protein of photosystem I & 0.64 & 7.68E-03 \\
\hline & A8ITV3 & LHCA9 & Light-harvesting protein of photosystem I & 0.79 & $8.00 \mathrm{E}-03$ \\
\hline & A8I0C6 & LHCA3 & Regulatory chlorophyll a/b binding protein & 1.74 & $3.47 \mathrm{E}-02$ \\
\hline & A8J431 & LHCSR3 & Stress-related chlorophyll a/b binding protein 2 & 0.16 & $1.27 \mathrm{E}-03$ \\
\hline & Q9ZSJ4 & LHCBM5 & Chlorophyll a-b binding protein of LHCII & 0.43 & 4.64E-03 \\
\hline & Q93WL4 & LHCBM3 & Light-harvesting chlorophyll-a/b binding protein LhcII-1.3 & 0.53 & 2.09E-03 \\
\hline & A8JCU4 & LHCBM1 & Chlorophyll a-b binding protein of LHCII & 0.34 & $1.46 \mathrm{E}-04$ \\
\hline & A8J287 & LHCBM6 & Chloropyll a-b binding protein of LHCII type I & 0.64 & $2.04 \mathrm{E}-02$ \\
\hline & A8J270 & LHCBM8 & Chlorophyll a-b binding protein of LHCII & 0.56 & 4.27E-03 \\
\hline & Q8S3T9 & Lhcbm9 & Chlorophyll a-b binding protein of LHCII & 0.68 & 4.44E-02 \\
\hline \multirow{3}{*}{$\begin{array}{l}\text { Alanine, } \\
\text { aspartate and } \\
\text { glutamate } \\
\text { metabolism }\end{array}$} & A8JFZ0 & SGA1a|SGA1b & Serine glyoxylate aminotransferase & 0.55 & $1.46 \mathrm{E}-02$ \\
\hline & A8IMN5 & CMPS1 & Small subunit of carbamoyl phosphate synthase & 1.91 & $9.09 \mathrm{E}-03$ \\
\hline & A8IVZ9 & GLN2/GS2 & Glutamine synthetase & 1.85 & 2.27E-05 \\
\hline
\end{tabular}


bioRxiv preprint doi: https://doi.org/10.1101/2022.02.23.481610; this version posted February 24, 2022. The copyright holder for this preprint (which was not certified by peer review) is the author/funder, who has granted bioRxiv a license to display the preprint in perpetuity. It is made available under aCC-BY-NC-ND 4.0 International license.

\begin{tabular}{|c|c|c|c|c|c|}
\hline \multirow{10}{*}{$\begin{array}{l}\text { Sulfur } \\
\text { metabolism }\end{array}$} & A8I263 & AST3 & Aspartate aminotransferase & 1.71 & 5.04E-03 \\
\hline & A8HXW8 & AST4 & Aspartate aminotransferase & 2.11 & $1.80 \mathrm{E}-02$ \\
\hline & A8JE06 & CHLREDRAFT_122298 & Predicted protein & 1.66 & $1.44 \mathrm{E}-02$ \\
\hline & A8IW34 & PURA & Adenylosuccinate synthetase & 2.33 & $9.86 \mathrm{E}-04$ \\
\hline & A8J3Q6 & APK1 & Adenylyl-sulfate kinase & 0.64 & $6.72 \mathrm{E}-03$ \\
\hline & A8J6A7 & APR1/MET16 & Adenylylphosphosulfate reductase & 1.40 & $5.90 \mathrm{E}-04$ \\
\hline & A8I3V3 & ATS2 & ATP-sulfurylase & 0.62 & $4.34 \mathrm{E}-03$ \\
\hline & Q6QJE1 & SABC & Chloroplast ATP-binding protein & 0.56 & $2.43 \mathrm{E}-02$ \\
\hline & A8JDD3 & SAT2 & Serine O-acetyl transferase & 0.24 & $1.35 \mathrm{E}-02$ \\
\hline & A8IEE5 & OASTL3 & Cysteine synthase & 0.46 & $1.48 \mathrm{E}-02$ \\
\hline
\end{tabular}


Fig. 1

A

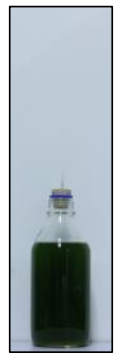

$1 \mathrm{~L}$

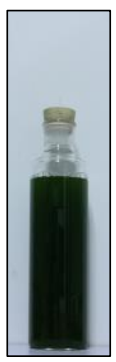

$2 \mathrm{~L}$

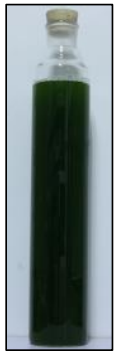

$3 \mathrm{~L}$
B

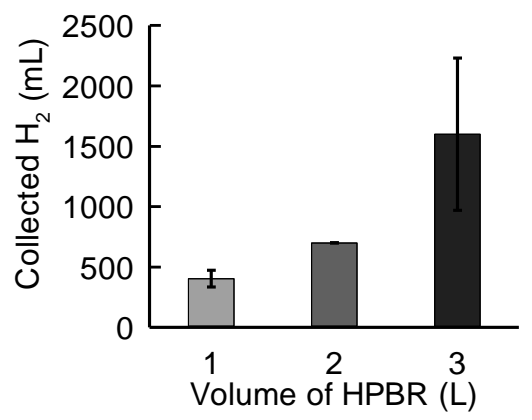

C

D
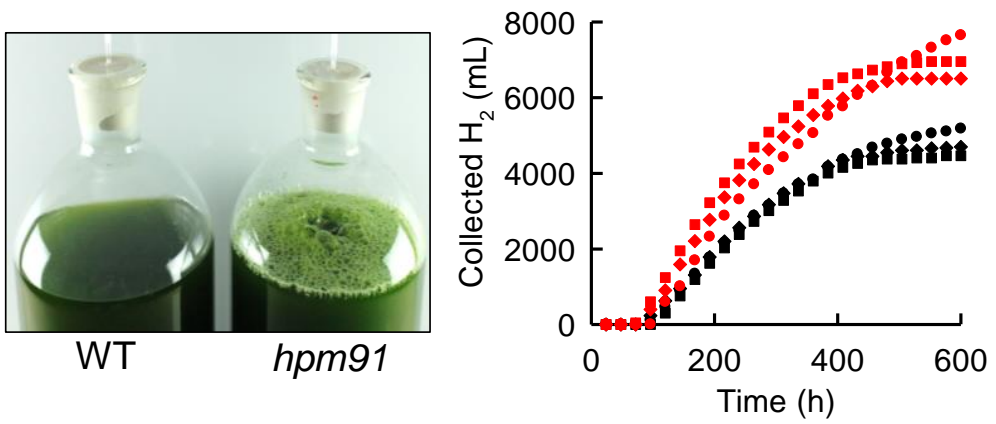
Fig. 2

A

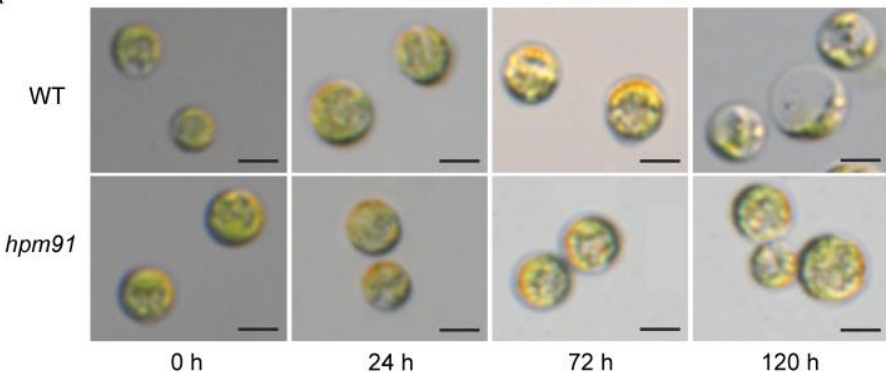

C

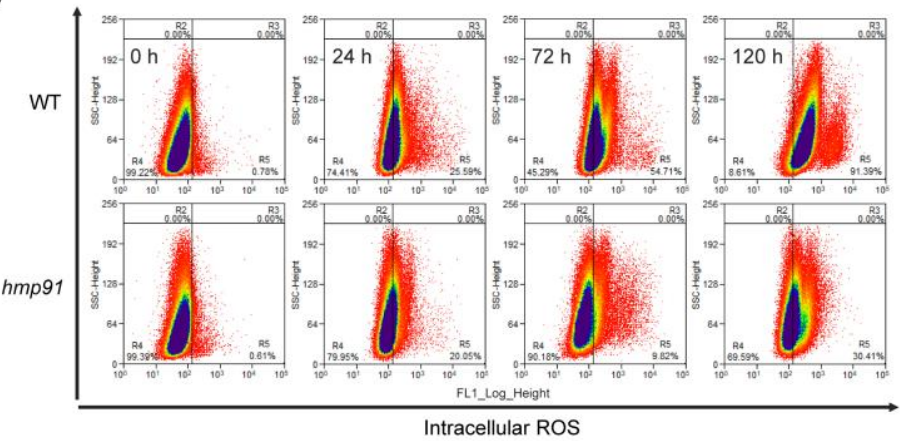

B

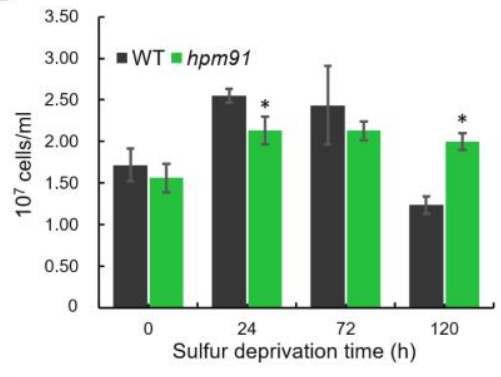

D

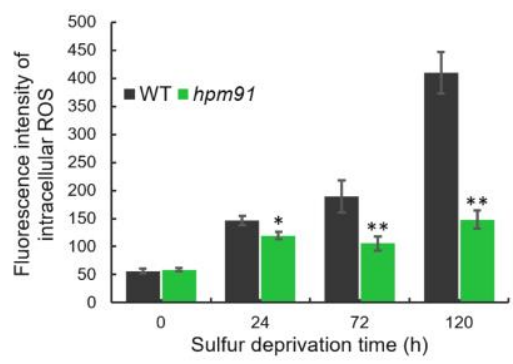


Fig. 3
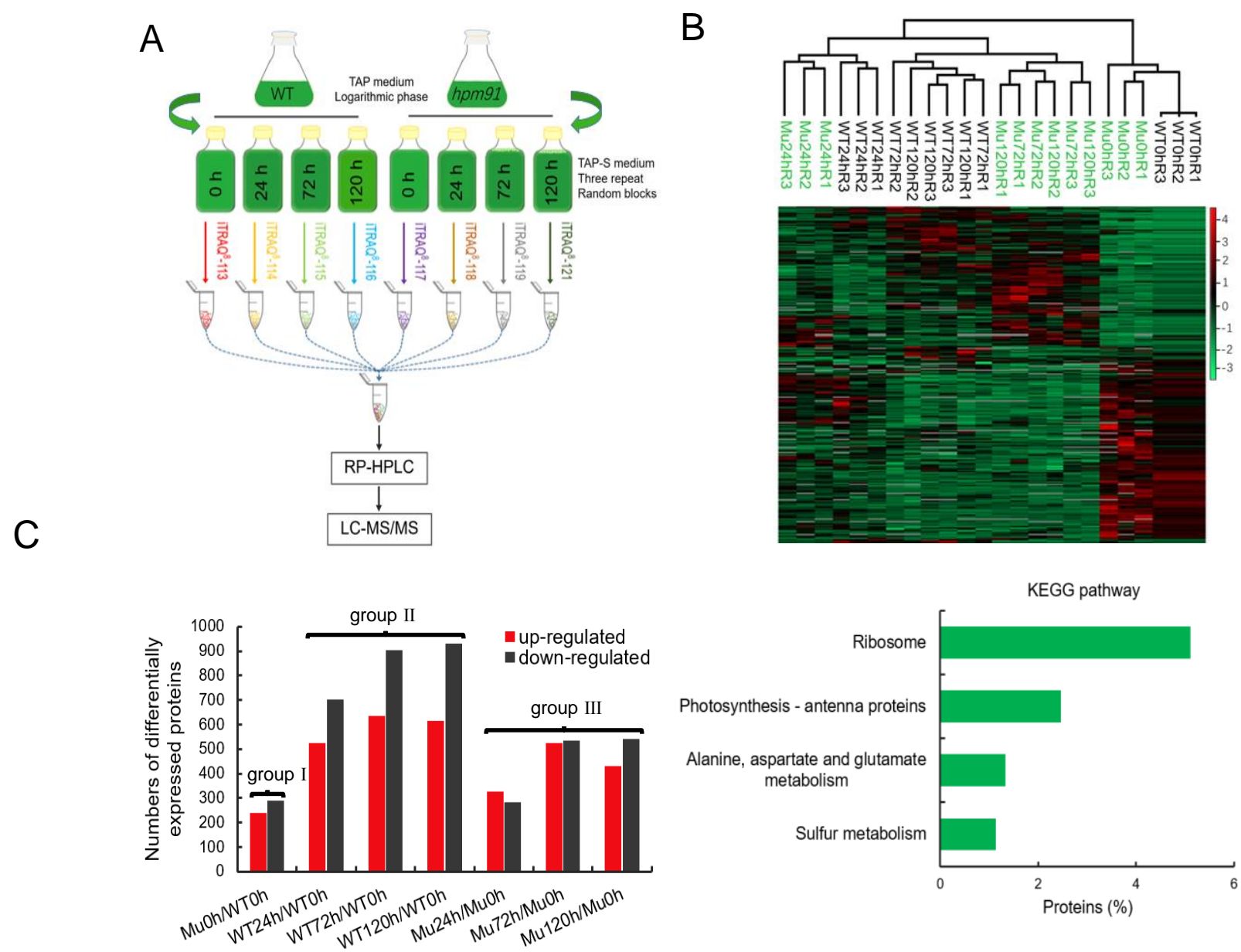
Fig. 4

A

Biological process

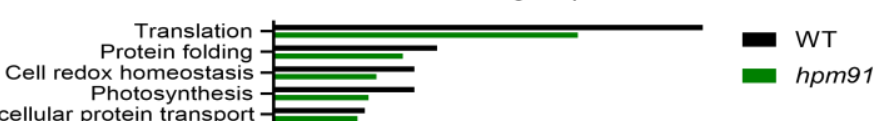

Intracellular prot

Intracellular protein transport
Carbohydrate metabolic process

Protein-chromophore linkage Response to cytokinin

Response to light stimulus

Ribosomal large subunit assembly

Chaperone-mediated protein folding Photosynthesis, Light harvesting in photosystem ICellular response to oxidative stress Tricarboxylic acid cycle

Chlorophyll biosynthetic process

Vesicle-mediated transport Sulfate assimilation ATP hydrolysis coupled proton transport Chloroplast organization ATP synthesis coupled proton transport Ribosomal small subunit assembly Cytoplasmic translation Cellular amino acid biosynthetic process
Translational initiation

Hydrogen peroxide catabolic process

One-carbon metabolic process

Response to reactive oxygen species De novo pyrimidine nucleobase biosynthetic processGluconeogenesis

Proline biosynthetic process Tryptophan biosynthetic process Carotenoid biosynthetic process Cellular amino acid metabolic process Fructose 6-phosphate metabolic process Terpenoid biosynthetic process Glyoxylate cycle -

B
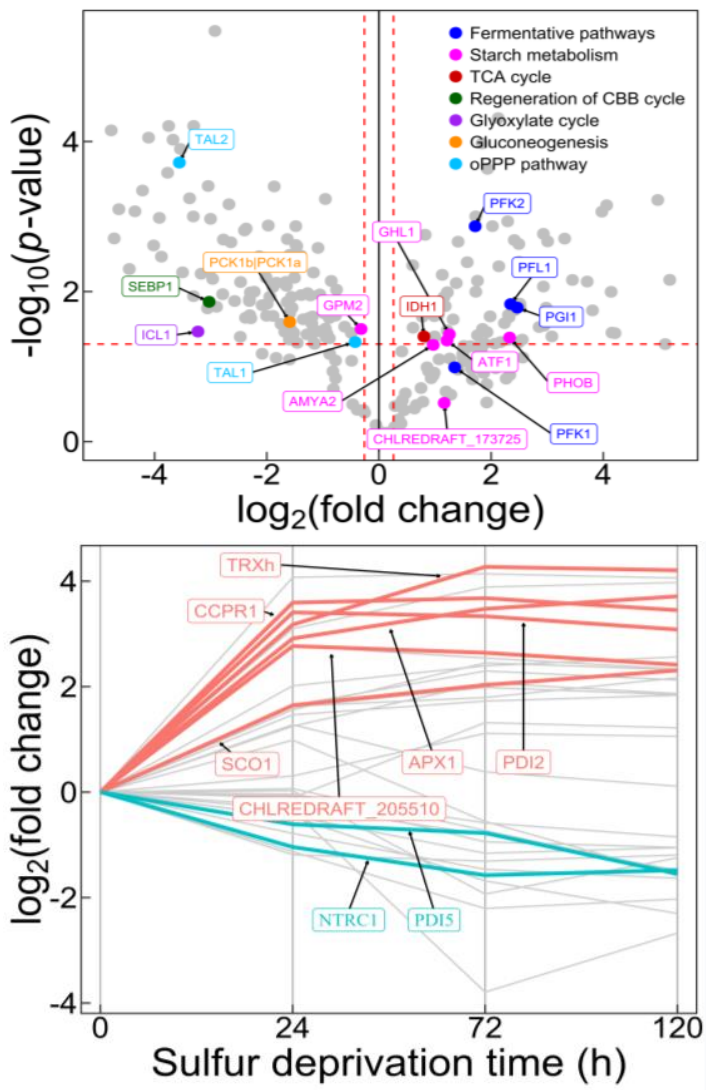

$50 \quad 100 \quad 150$

Protein number
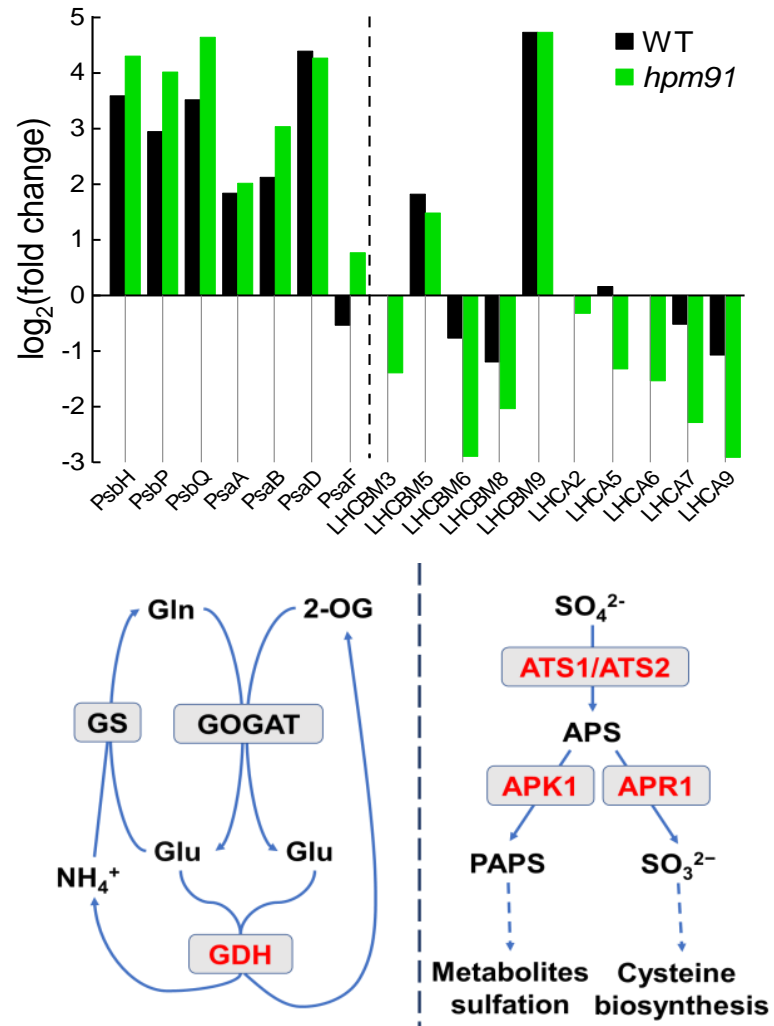
Fig. 5

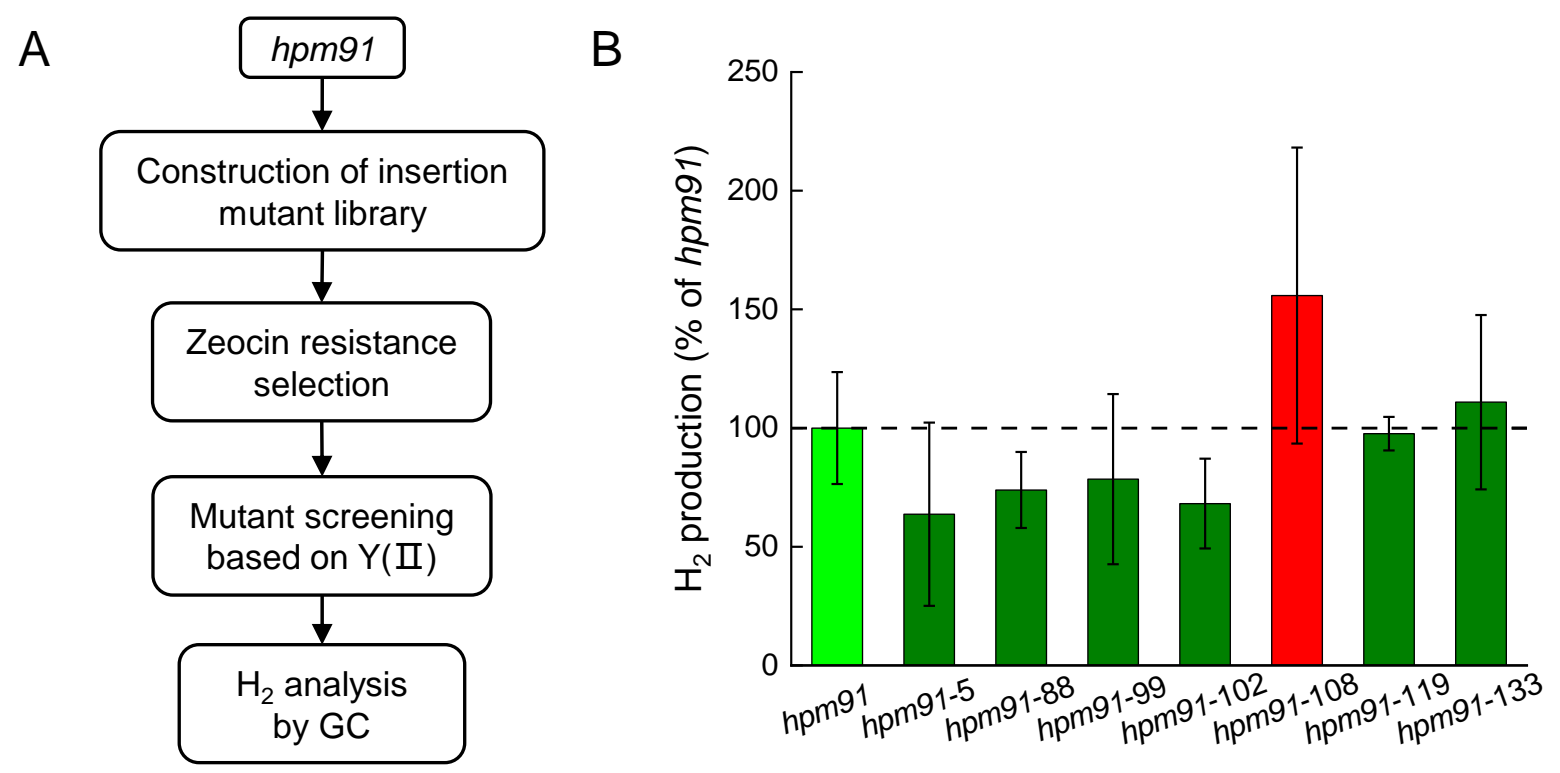

